\title{
BMJ Open Trends, patterns and predictive factors of infant and child mortality in well- performing and underperforming states of India: a secondary analysis using National Family Health Surveys
}

\author{
Mrigesh Bhatia, ${ }^{1}$ Laxmi Kant Dwivedi, ${ }^{2}$ Mukesh Ranjan, ${ }^{2}$ Priyanka Dixit, ${ }^{3}$ \\ Venkata Putcha ${ }^{4}$
}

To cite: Bhatia M, Dwivedi LK, Ranjan M, et al. Trends, patterns and predictive factors of infant and child mortality in wellperforming and underperforming states of India: a secondary analysis using National Family Health Surveys. BMJ Open 2019;9:e023875. doi:10.1136/ bmjopen-2018-023875

- Prepublication history for this paper is available online. To view these files, please visit the journal online (http://dx.doi. org/10.1136/bmjopen-2018023875).

Received 2 May 2018

Revised 17 January 2019

Accepted 31 January 2019

D) Check for updates

(c) Author(s) (or their employer(s)) 2019. Re-use permitted under CC BY-NC. No commercial re-use. See rights and permissions. Published by BMJ.

${ }^{1}$ Department of Health Policy, London School of Economics and Political Science, London, UK

${ }^{2}$ International Institute for Population Sciences, Mumbai, Maharashtra, India

${ }^{3}$ Tata Institute of Social

Sciences, Mumbai, Maharashtra, India

${ }^{4}$ SriV, Slough, UK

Correspondence to

Dr Mrigesh Bhatia;

m.r.bhatia@lse.ac.uk

\section{ABSTRACT}

Objectives This paper analyses the patterns and trends in the mortality rates of infants and children under the age of 5 in India (1992-2016) and quantifies the variation in performance between different geographical states through three rounds of nationally representative household surveys.

Design Three rounds of cross-sectional survey data. Setting The study is conducted at the national level: India and its selected good-performing states, namely Haryana, Kerala, Maharashtra, Punjab and Tamil Nadu, and selected poor-performing states, namely Bihar, Chhattisgarh, Madhya Pradesh and Uttar Pradesh.

Participants Adopting a multistage, stratified random sampling, 601509 households with 699686 women aged 15-49 years in 2015-2016, 109041 households with 124385 women aged 15-49 years in 2005-2006, and 88562 households with 89777 ever married women in the age group 13-49 years in 1992-1993 were selected.

Results Through the use of maps, this paper clearly shows that the overall trend in infant and child mortality is on a decline in India. Computation of relative change shows that majority of the states have witnessed over $50 \%$ reduction in both infant and under -5 mortality rates from National Family Health Survey (NFHS)-I to NFHS-4. However, the improvements are not evenly distributed, and there is huge variation in performance between states over time. Funnel plots show that the most populous states like Uttar Pradesh Bihar and Madhya Pradesh have underperformed consistently across the survey period from 1992 to 2016 . Regression analysis comparing high-performing and low-performing states revealed that female infants and women with shorter birth intervals had greater risk of infant deaths in poorperforming states.

Conclusion Attempts to reduce infant and child mortality rates in India are heading in the right direction. Even so, there is huge variation in performance between states. This paper recommends a mix of strategies that reduce child and infant mortality among the high-impact states where the biggest improvements can be expected, including the need to address neonatal mortality.
Strengths and limitations of this study

- The study shows trends in infant and under-5 mortality rates from 1992 to 2016 using three rounds of data covering most of India.

- A more effective approach using funnel plots quantified the variation in performance of states with respect to child mortality rates.

- This study attempts to understand how factors associated with infant deaths act differently in underperforming and well-performing states.

- Limitations in analysis based on secondary data also apply to this study.

- As a result of grouping of states, some state-specific factors affecting infant mortality may get diluted.

\section{INTRODUCTION}

Child health is a basic right, and the level of child mortality is an important indicator in the assessment of the development of any society. ${ }^{1}$ It is therefore not surprising that the United Nations' Sustainable Development Goals declaration (2015) to improve the health and welfare of the world's poorest people includes reducing child mortality as one of its goals, which was earlier laid out by the Millennium Development Goals (MDG) declaration (1990). ${ }^{2}$ Annually, 5.6 million children under the age of 5 die worldwide, primarily in low-income and middle-income countries. ${ }^{3}$ Given that most of these deaths can be easily prevented or treated ${ }^{4}$ with cheap and effective interventions, such high mortality is unacceptable even in resource-constrained settings.

India is the world's largest democratic nation, with $16 \%$ of the global population. According to Unicef, India has the highest number of under-5 deaths, with a total of 1.08 million deaths in $2016 .^{5}$ It is one of the six countries 
that contribute to $50 \%$ of the world's under- 5 mortality rate (U5MR). ${ }^{5}$ On its own, India contributes to $19 \%$ of all under-5 deaths and $24 \%$ of all neonatal deaths. ${ }^{5}$ However, infant mortality rate (IMR) and U5MR have declined over the years in India. For example, U5MR reduced from 114 per 1000 live births in 1990 to 39 in 2016 at an annual rate of $3 \%{ }^{5}$ Similarly, IMR reduced from 81 to 34 per 1000 live births between 1990 and 2016. ${ }^{5}$ However, the distribution of these gains is uneven across states. ${ }^{6}$ For example, at the national level, U5MR is estimated at 39 , and it varies from 43 in rural areas to 25 in urban areas. Among the bigger states/union territories, it varies from 11 in Kerala to 55 in Madhya Pradesh (MP). ${ }^{6}$ Similarly, at the national level, IMR is reported to be 34 , and varies from 38 in rural areas to 23 in urban areas. Among the four most populated states, it varies from 38 in Bihar to 47 in MP. ${ }^{6}$

Healthcare in India is the responsibility of individual states, which vary in terms of their level of socioeconomic development, size of population, experience of epidemiological transition and health system capacities, factors which influence the health status experienced by the population of the states. On the one hand, states like Kerala experience relatively low levels of infant and child mortality comparable with the Western world, whereas states like MP and Uttar Pradesh (UP) suffer IMRs and U5MRs comparable with some of the poorest countries of the world. ${ }^{7}$ Therefore, it is necessary to disaggregate the mortality data and quantify the variation between states. This would help policy makers to prioritise the underperforming states where intense efforts need to be expanded.

By providing the current status of child mortality through the use of maps, and undertaking a disaggregate analysis of infant mortality using the funnel plot technique, this paper identifies key states where performance needs to improve significantly and the states that should be the target of intense efforts in the future. Funnel plots are an attractive way to present data to policy makers and a good tool to compare performance data, including population data. ${ }^{8}$ Funnel plots have been used in the developed world in a number of settings, including assessing institutional performance, ${ }^{9}$ comparing healthcare providers, ${ }^{10}$ and assessing variations in cardiac ${ }^{11} 12$ and cancer mortality. ${ }^{13}{ }^{14}$ However, to the best of our knowledge, the application of this technique to child mortality rates in the context of low-income and middle-income countries has not been previously conducted.

This paper is timely in that the National Family Health Survey (NFHS)-4 survey data (2015-2016) have just been released in January 2018. In addition, India is the highest contributor to U5MR in the world, and with new impetus in reducing child and maternal mortality the rest of the world is closely monitoring India's performance.

\section{METHODS}

\section{Data}

The analysis in this paper is based on three rounds of NFHS: NFHS-1, NFHS-3 and NFHS-4 data, which were conducted during the periods between 1992 and 1993, 2005 and 2006, and 2015 and 2016. For pragmatic reasons, NFHS-2 survey data conducted in 1998-1999 have been intentionally excluded from our analysis. An important consideration for not including NFHS-2 survey in the analysis is the short time interval between 1992-1993 and 1998-1999 and that there were no major changes with respect to policies and programmes during this period. The International Institute for Population Sciences is designated as a nodal agency for conducting the survey under the stewardship of the Ministry of Health and Family Welfare, Government of India (GOI). The NFHS series provides information on population, health and nutrition for India and each state/union territory. NFHS-4 gathered information from 601509 households, 699686 women and 103525 men. ${ }^{15}$ In NFHS-3, interviews were conducted with 124385 women aged 15-49 and 74369 men aged 15-54 from all 29 states. ${ }^{16}$ NFHS-1 is a household survey which has a nationally representative sample of 88562 households and 89777 ever married women in the age group 13-49 years covering the population in 24 states and the National Capital Territory of Delhi. ${ }^{17}$ It may be noted that we have merged the sample for union territories into their nearby states, such as Andaman and Nicobar Islands and Puducherry merged into Tamil Nadu; Dadra and Nagar Haveli into Maharashtra; Daman and Diu into Gujarat; Lakshadweep into Kerala; and Chandigarh into Punjab. The states of Chhattisgarh and Jharkhand were modelled based on district information available in NFHS-1 to make it comparable with NFHS-3 and NFHS-4. However, it was not possible to separate out the state of Telangana from NFHS-3. The present study has used 10 years of retrospective birth history information to estimate the mortality rates. The information related to births and deaths which women had during their reproductive period is collected from the NFHS surveys. Further, the information collected on deaths and age at death of child was consistent across all rounds of NFHS. ${ }^{18}$ Literature suggests that omission of births is almost virtually nil, but displacement of births in reporting of the age of child is visible in these surveys. ${ }^{19}$

\section{Statistical analysis}

Maps were drawn to study the patterns of IMR and U5MR across the states of India, and trends were studied between the three survey time points. Funnel plots were drawn to observe the variation in performance between states. The all-India average IMR (indicated by a solid line parallel to the $\mathrm{x}$-axis) was used as a baseline reference. The $99 \%$ confidence bands were constructed, and each data point represents the state's IMR. The states which are located above the $99 \%$ band in the funnel plot are considered as underperforming states, and those which are located below are considered as well-performing states. The states Haryana, Kerala, Maharashtra, Punjab and Tamil Nadu fall under the category of good-performing states. The poor-performing states are Bihar, Chhattisgarh, MP and 


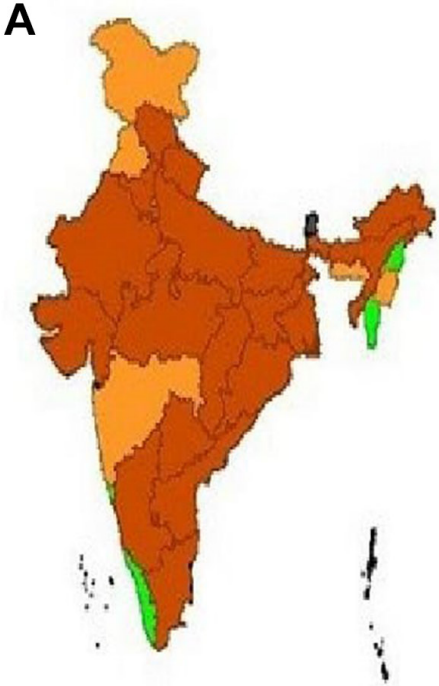

NFHS-1 (1992-93)
B

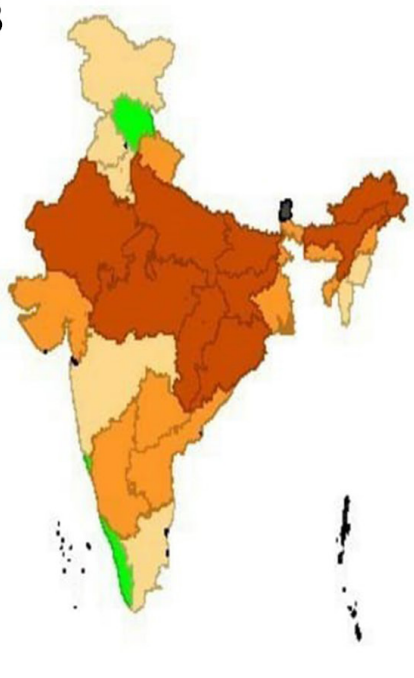

NFHS-3 (2005-06)

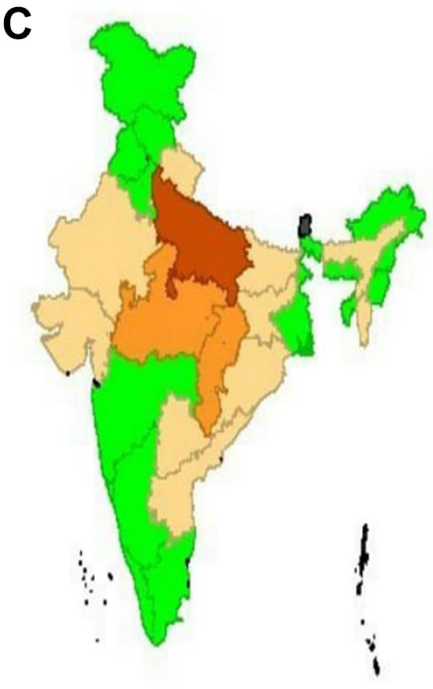

NFHS-4 (2015-16)

Figure 1 Trends in under-5 mortality rate for India and states. NFHS, National Family Health Survey.

UP. In addition, we have compared the results of $99 \%$ confidence bands with $95 \%$.

The dependent variable for the present study is considered as infant death, which is coded as 1 'if the death occurred less than 1 year' and 0 'otherwise'. Births which took place preceding 5 years from the date of survey have been considered for the analysis. The following independent variables have been taken: sex of the child (male, female), mothers' age at child's birth divided into six categories (15-19, 20-24, 25-29, 30-34, 35-39, 40-50), mothers' education (illiterate, primary, secondary, higher), caste of women (scheduled caste [SC], scheduled tribe [ST], other than $\mathrm{SC}$ and $\mathrm{ST}$ ), religion of women (Hindu, Muslim, Others), combination of birth interval and birth order (first birth order, two or more birth order and less than 24 months, two or more birth order and more than 24 months), region of residence (rural, urban), wealth index (poorest, poorer, middle, richer, richest), and body mass index (low, high, missing).

The first category of each covariate is considered as a reference category. Further, for poor-performing states (Bihar, Chhattisgarh, MP, UP), Bihar is considered as a reference category. For good-performing states (Kerala, Haryana, Maharashtra, Punjab and Tamil Nadu), Kerala is considered as a reference category in a separate regression model.

Cox regression analysis has been employed to examine the factors ${ }^{20}$ which are responsible for explaining the infant deaths in underperforming and well-performing states using the recent round of NFHS-4 data. Based on the results of funnel plots of $99 \%$ confidence, the underperforming states considered for the regression analysis are Bihar, Chhattisgarh, MP and UP. Similarly, the well-performing states considered are Haryana, Kerala, Maharashtra, Punjab and Tamil Nadu. For the regression analysis, only the recent round of NFHS- 4 data has been considered.

The brief mathematical description of this model is given below:

Let $\mathrm{X}_{1}, \mathrm{X}_{2}, \mathrm{X}_{3}, \ldots \mathrm{X}_{\mathrm{p}}$ be $\mathrm{p}$ predictors which affect the dependent variable, that is, infant deaths. Further, suppose that hazards at time $t$ is $\lambda(t)$, then Cox proportional hazards model is generally written in the form of:

$$
\lambda(\mathrm{t})=\lambda_{0}(\mathrm{t}) \exp \left(\beta_{1} \mathrm{X}_{1}+\beta_{2} \mathrm{X}_{2}+\ldots+\beta \mathrm{pXp}\right)
$$

$$
\begin{gathered}
=\lambda_{0}(t) \exp \left(\sum_{i=1}^{p} \beta_{i} X_{i}\right) \\
=\lambda_{0}(t) e^{\sum_{i=1}^{p}\left(\beta_{i} x_{i}\right)}
\end{gathered}
$$

where $\lambda_{0}(t)$ is baseline hazard at time $t$, and $\beta_{1}, \beta_{2}, \ldots$ $\beta_{\mathrm{p}}$ are unknown regression coefficients. The advantage of hazards model is that exponential expression permits the specification of the model without any further restrictions on the covariates. The baseline hazard is a function of $t$, but does not involve the X's (covariates) (Cox, 1972). ${ }^{20}$

All analyses were performed in STATA V.13.1 software.

\section{Patient and public involvement statement}

Participants were not involved in the design of this study. The manuscript is based on the analysis of secondary data of the NFHS I-4 series, which is available in a public domain.

\section{RESULTS}

Maps identifying the pattern and trend in IMR and U5MR across the states of India are presented in Figures 1-2. Figures 1 and 2 show that IMR and U5MR have declined in India in absolute terms and in terms of distribution across states over the years between the NFHS-I and the NFHS-4 


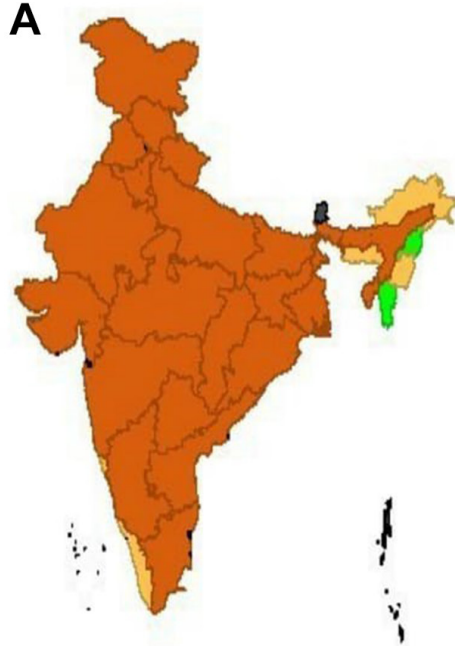

NFHS-1 (1992-93)

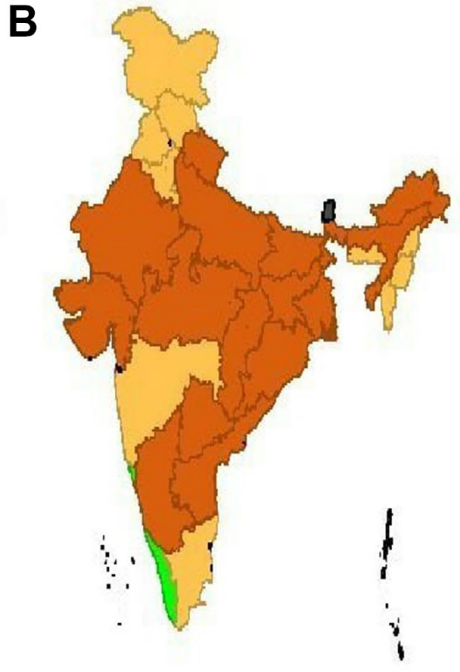

NFHS-3 (2005-06)

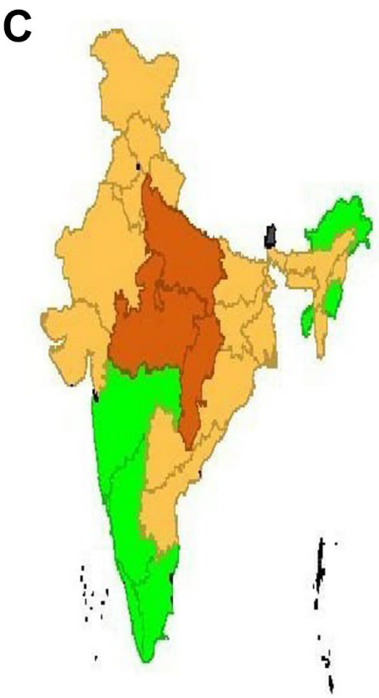

NFHS-4 (2015-16)

Figure 2 Trends in infant mortality rate for India and states. NFHS, National Family Health Survey.

surveys. At a glance, it can be observed from figure 1 that majority of the states (ie, 19) experienced U5MR of over 80 per 1000 live births in NFHS-I compared with only one state in NFHS-4. The same holds true for IMR. From figure 2 it can be observed that most of India experienced IMR of over 50 per 1000 live births in NFHS-I, whereas hardly any state experiences such IMRs today.

Figures 1 and 2 also show the number of states achieving MDG targets of 29 and 43 per 1000 live births, which were set as a goalpost for India for IMR and U5MR, respectively. While IMR of less than 29 per 1000 live births and U5MR of less than 43 per 1000 live births were restricted to a few small states in terms of population in NFHS-I, this is not so in NFHS-4. There are significantly more states with low IMR and U5MR, and this trend is not restricted to less populated states. By examining the MDG targets for each state of India, it can be observed that only Kerala, Tamil Nadu and Tripura have achieved the targets of reducing its IMR by two-thirds from 1990. Surprisingly, none of the states have achieved its goal of U5MR.

Table 1 presents the IMR and U5MR for NFHS1-4 survey periods from 1992 to 2016, along with relative change in IMR and U5MR in Indian states. It can be observed that the trend in IMR is in decline significantly from $86(95 \%$ CI 84 to 88) in NFHS-I to 42 (95\% CI 41 to 43) per 1000 live births in NFHS-4. During NFHS-I, the overall IMR for India was 86 per 1000 live births, varying from $12(95 \%$ CI 7 to 17) in Nagaland to 119 (95\% CI 113 to 126) in Odisha. States like UP, Odisha, Bihar and MP reported an IMR of over 100 per 1000 live births. Similarly, NFHS-3 witnessed an overall IMR of 65 (95\% CI 63 to 67) per 1000 live births, varying from 18 (95\% CI 12 to 23) in Kerala to 83 (95\% CI 78 to 88) in UP. States like UP, Chhattisgarh and MP reported an IMR of over 80 per 1000 live births. Lastly, NFHS-4 reported an overall IMR of 42 per 1000 live births, varying from 7 (95\% CI 4 to 9) in Kerala to 64
(95\% CI 63 to 66) in UP. States like UP, Chhattisgarh and MP reported an IMR of over 50 per 1000 live births.

Table 1 also presents the results of a relative change in IMR and U5MR across survey periods. For survey periods NFHS-1 to NFHS-3, the overall reduction in IMR was 25\%, and this varied from less than $2 \%$ in Jharkhand to $47 \%$ in Tamil Nadu. Similarly, during NFHS-1 to NFHS-4, the overall reduction in IMR was $51 \%$, and this varied from less than 36\% in Meghalaya and Jammu and Kashmir to $79 \%$ in Kerala. It can be observed that majority of the states have witnessed over $50 \%$ reduction in both IMR and U5MR from NFHS-I to NFHS-4. The maximum benefits in terms of reduction in infant deaths were observed in Kerala, Odisha, Tamil Nadu, West Bengal, Karnataka, Goa, Tripura and Haryana, whereas Chhattisgarh, Meghalaya, and Jammu and Kashmir observed the least improvements in infant mortality. Surprisingly two states, namely Mizoram and Nagaland, had in fact experienced an increase in IMR over the two survey periods. Similar pattern was observed in U5MR. It may be noted that most of the reductions in both IMR and U5MR were seen between the NFHS-3 and NFHS-4 survey periods.

Having observed the general pattern and trends in infant and U5MR in India, it would be useful to see the variation in performance of the various states. Figure 3A-C presents the funnel plots for NFHS-I, NFHS-3 and NFHS-4 survey periods, which help to identify the states with the lowest IMR and the states with the highest IMR, compared with the Indian average figures as indicated by a solid line parallel to the x-axis. The overall Indian IMR was used as a baseline comparison for each state. It can be observed that plots closer to the y-axis are low birth states (small populated states) and those to the right are high birth states (large populated states). Data points that lie outside the CI band are interpreted as experiencing IMR differently from the Indian average. Those states outside 


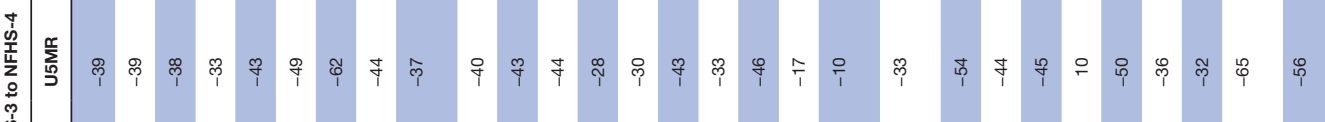

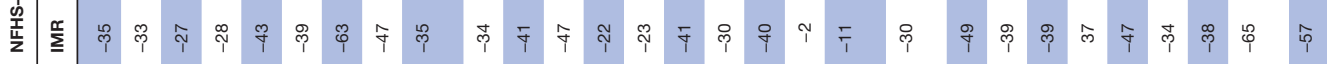

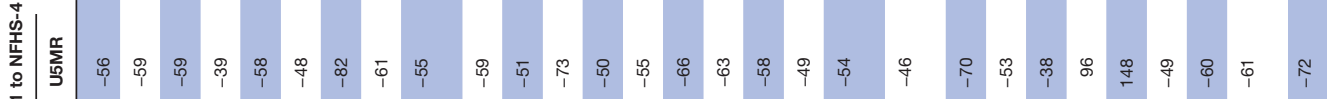

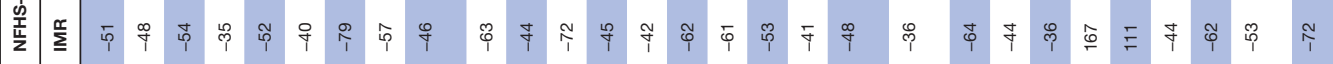

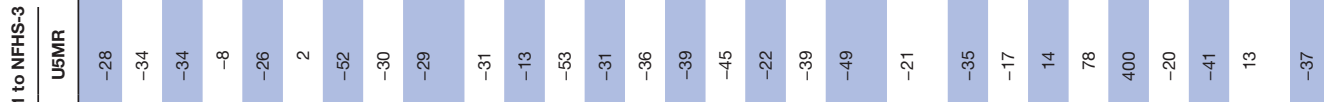

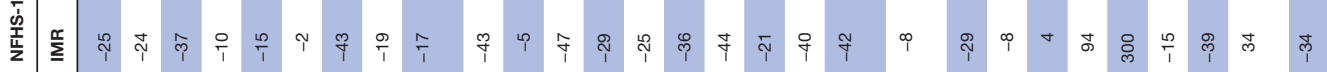

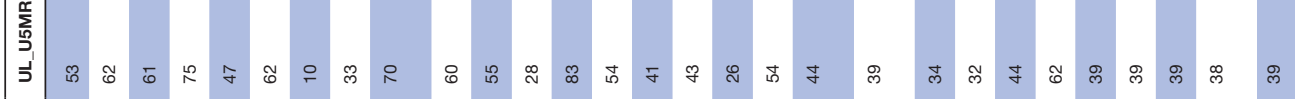
离

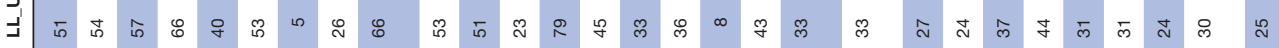

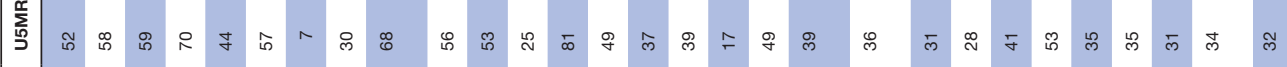

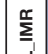

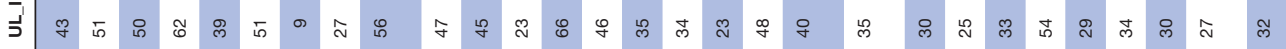

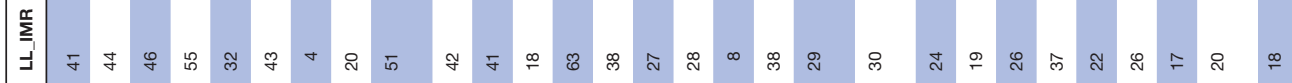

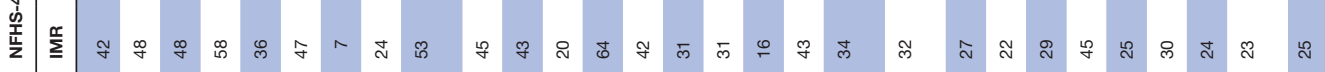

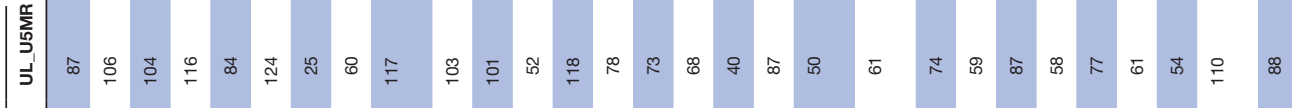

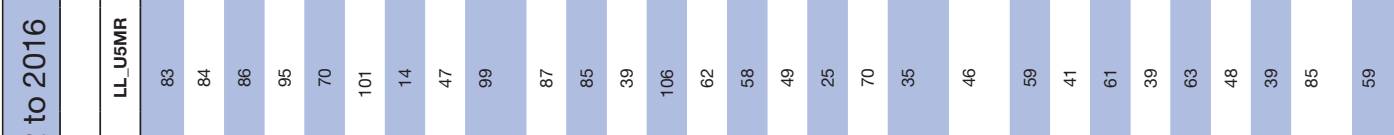
年 旁

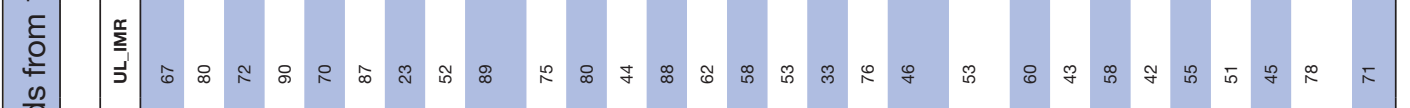

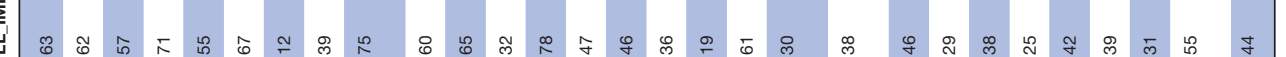

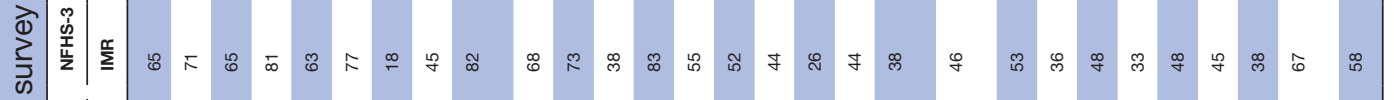

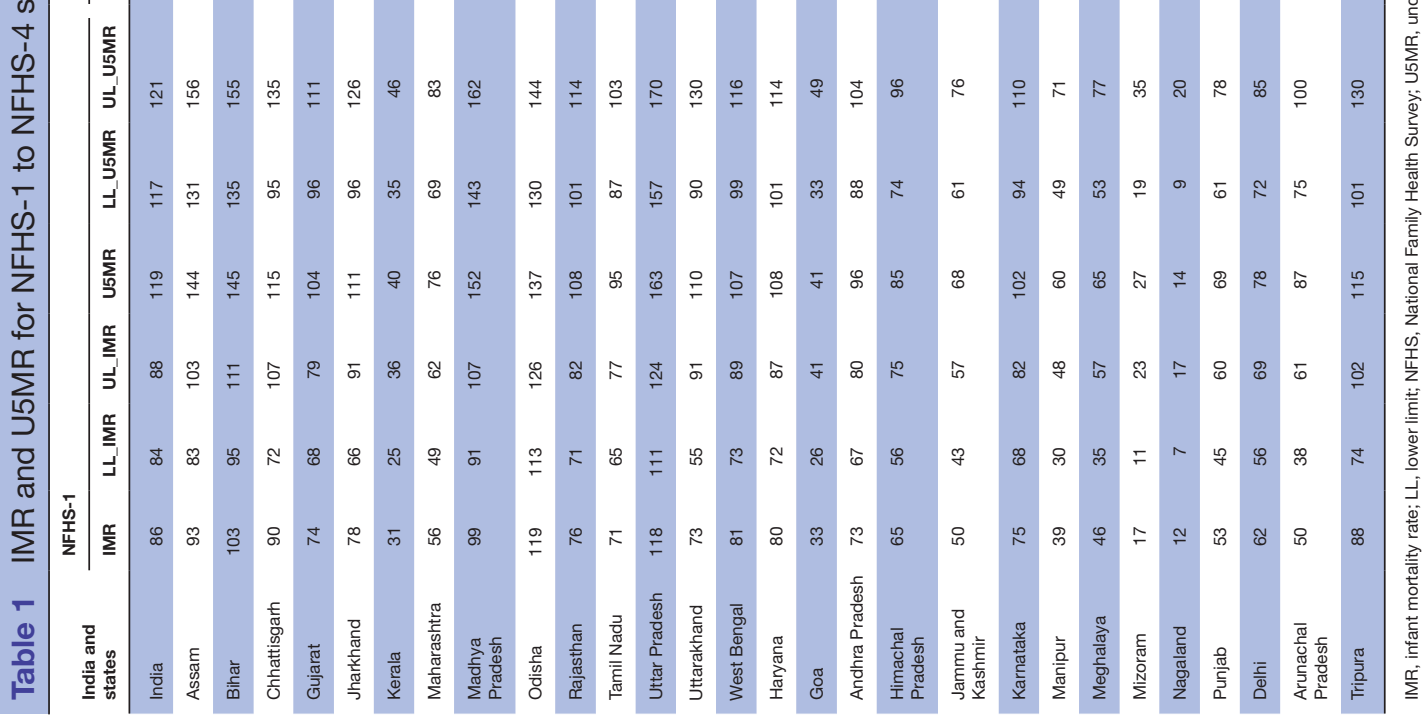




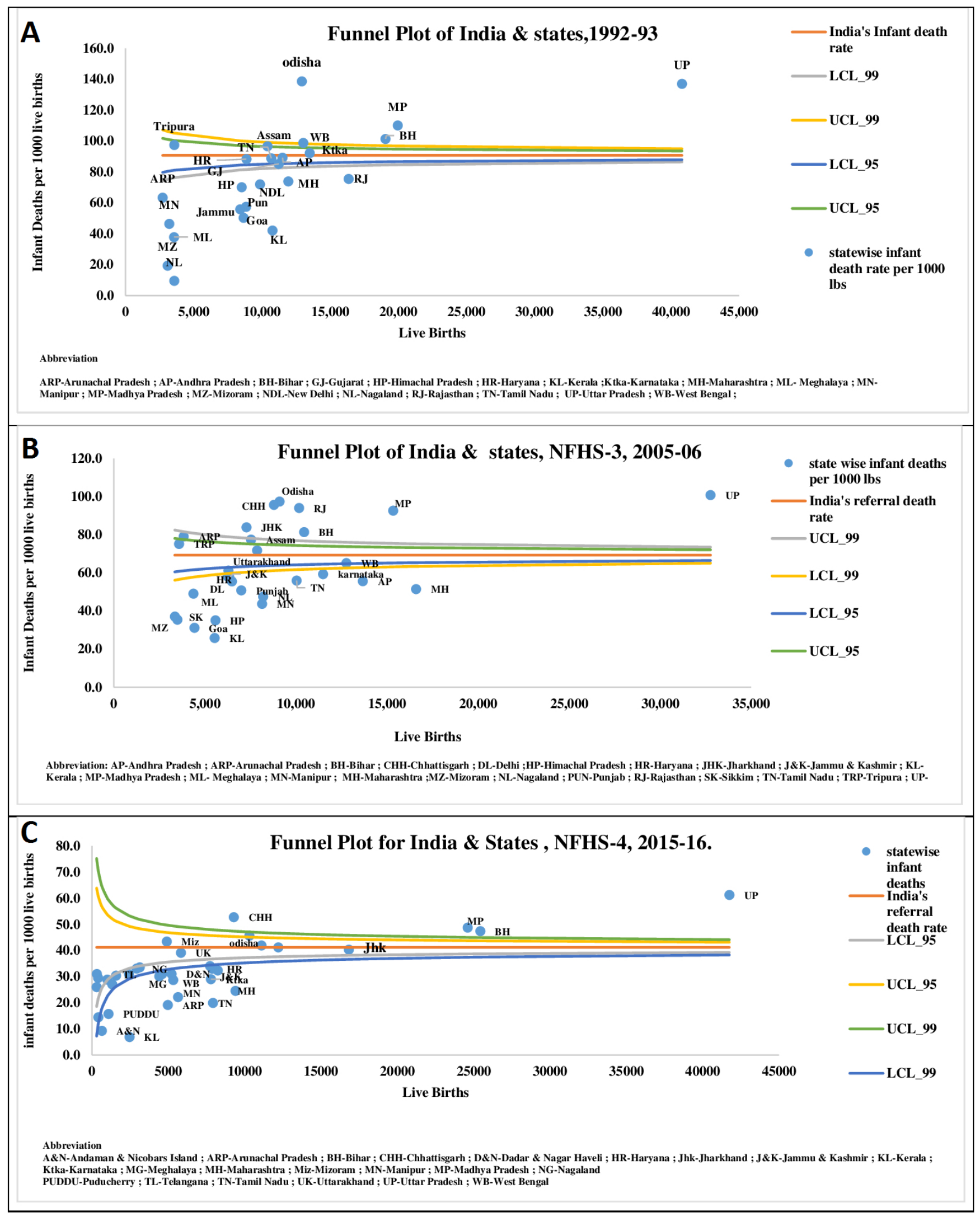

Figure 3 (A-C) Funnel plots for India and states. LCL, lower confidence interval; NFHS-1, 3 and 4, National Family Health Survey; UCL, upper confidence interval. 
the $99 \%$ CI can be considered as outliers in terms of their performance with respect to IMR. States which are above the Indian average are the worst-performing states and those below are the best-performing states in terms of IMR.

Figure 3A also shows a huge variation in the performance of the states with respect to IMR in NFHS-I. Of the 21 major states, four states, namely UP, Odisha, Bihar and MP, are performing so poorly with respect to IMR that they lie above the upper limits of the distribution of the funnel plot, which has been created at $99 \%$ confidence bands. It may be noted that with respect to $95 \%$ band, Assam is the only state to also be included in the category of poor-performing states. The majority of the states were below the overall Indian baseline at 99\% bands. Figure 3B presents data for NFHS-3, where it can be observed that in addition to the four states mentioned above, additional states like Rajasthan, Jharkhand and Chhattisgarh are also outliers at $99 \%$ bands. Lastly, figure 3C presents data for NFHS-4, where improvements are observed in performance of states, with only four underperforming states, namely MP, Bihar, UP and Chhattisgarh.

From the above it can be observed that there is a huge variation in performance among the states. These results hold true for both IMR and U5MR. UP, Bihar and MP warrant special mention as these states are the most populous states in India and have underperformed consistently across the survey period from 1992 both with respect to IMR and U5MR.

Data (not shown) show the percentage distribution of infant deaths by some selected background characteristics in India. There were a total of 9792 infant deaths that took place in a period of 5 years prior to the survey. Of the total infant deaths, nearly $56 \%$ were male and the rest were female. Nearly $70 \%$ of the total infant deaths occurred to mothers who were in the age group 20-29 years at the time of childbirth. Contrary to expectation, trend with respect to education is not clear-cut. Illiterate mothers and those who had secondary education experienced high infant mortality. More than four-fifths of infant deaths took place in rural areas. Nearly $60 \%$ of the total infant deaths occurred to mothers who belonged to the poorest and poorer wealth groups, and only $20 \%$ of the total infant deaths occurred to the richer and richest mothers. The gradient with respect to wealth index is clear. Those who are least well off (poorest 20\%) experienced three times infant deaths when compared with the richest $20 \%$. Nearly one-third of infant deaths were of first order, and $34 \%$ of infant deaths were of two and higher birth order and had birth interval of more than 24 months. Of the total infant deaths, nearly $28 \%$ occurred in UP, $15 \%$ in Bihar and 9\% in MP, respectively. Finally, it may be noted that five states, namely UP, MP, Bihar, Rajasthan and West Bengal, contribute over $65 \%$ of the total infant deaths in India.

We estimate two separate multivariable regression models to examine the significant factors affecting infant mortality (table 2). The first and second models display the adjusted effect of selected covariates on infant deaths in good-performing and poor-performing states, respectively. Among the good-performing states, infants from Haryana and Punjab had higher risk of infant death as opposed to Kerala. However, in the case of poor-performing states, MP and UP had higher risk of infant deaths in comparison with Bihar. Place of residence, mothers' body mass index, caste and religion of women had insignificant association with infant deaths in both models. Female child had higher chance of infant deaths in the group of poor-performing states, but no significant association was found in the case of good-performing states. Mothers' age at birth had no role in the case of good-performing states, but the risk of infant deaths was low in the 20-29 years age group in the case of poor-performing states. Women who had shorter birth interval had higher chance of experiencing infant deaths in the poor-performing states, and it was not significant in the case of good-performing states. Mothers' education had significant role in both groups of states. As educational level increases, the chances of experiencing infant deaths decrease. Women who belong to the richest wealth quintile had 39\% lower chance of experiencing infant deaths in the group of poor-performing states.

\section{DISCUSSION}

The analysis in this paper is based on U5MR and IMR estimates from NFHS surveys from the 1992-2016 period. IMR is defined as the number of infant deaths per 1000 live births and is one of the indicators used to assess a country's overall level of development. ${ }^{21}$

Through the use of maps, this paper clearly shows that the overall trend in IMR and U5MR in India is decreasing and thus headed in the right direction. Reduction in infant and child mortality among states was observed over time from the NFHS- 1 to the NFHS-4 survey periods. Smaller populated states already show a significant reduction in IMR. However, much effort still needs to be done in the heavily populated states, where mortality decline has been at a much slower pace than expected as these states continue to remain outliers in spite of a number of policy initiatives.

Maps are powerful tools in presenting the trends and the current distribution of child mortality across states. However, what is more useful to policy makers is to have a tool that can provide information at a glance about the size of the states in terms of population and help identify the states that are outliers in terms of their performance with respect to child mortality. Funnel plots are one such tool that we used in identifying underperforming states. Similar to prior studies, our results show that hugely populated and least developed states like UP, MP and Bihar still contribute significantly to India's overall high IMR and U5MR. ${ }^{72}$ In spite of reduction in child deaths in these states over the years, even today, these three states alone contribute to over $50 \%$ of all infant deaths in India. Unfortunately, as seen in the funnel plots, these three 
Table 2 Adjusted HR for infant mortality preceding 5 years from the date of survey by selected characteristics according to well-performing and poor-performing states in India, 2015-2016

\begin{tabular}{|c|c|c|c|c|c|c|}
\hline \multirow[b]{3}{*}{ Covariates } & \multicolumn{3}{|c|}{ Good-performing states } & \multirow[b]{3}{*}{ HR } & \multirow{2}{*}{\multicolumn{2}{|c|}{$\begin{array}{l}\text { Poor-performing state } \\
95 \% \mathrm{Cl} \text { for } \exp (\beta)\end{array}$}} \\
\hline & \multirow[b]{2}{*}{ HR } & \multicolumn{2}{|c|}{$95 \% \mathrm{Cl}$ for $\exp (\beta)$} & & & \\
\hline & & Lower & Upper & & Lower & Upper \\
\hline \multicolumn{7}{|l|}{ States } \\
\hline \multicolumn{7}{|l|}{ Kerala (good-performing states) $†$} \\
\hline Haryana & $3.57^{\star \star \star}$ & 1.51 & 8.43 & NA & NA & NA \\
\hline Maharashtra & 1.88 & 0.79 & 4.49 & NA & NA & NA \\
\hline Punjab & $2.62^{\star \star}$ & 1.05 & 6.55 & NA & NA & NA \\
\hline Tamil Nadu & 1.86 & 0.77 & 4.50 & NA & NA & NA \\
\hline Bihar (poor-performing states) $\dagger$ & NA & NA & NA & & & \\
\hline Chhattisgarh & NA & NA & NA & 1.23 & 0.96 & 1.59 \\
\hline MP & NA & NA & NA & $1.46^{\star \star \star}$ & 1.23 & 1.74 \\
\hline UP & NA & NA & NA & $1.93^{\star \star \star}$ & 1.67 & 2.23 \\
\hline \multicolumn{7}{|l|}{ Place of residence } \\
\hline \multicolumn{7}{|l|}{ Rural† } \\
\hline Urban & 1.15 & 0.85 & 1.54 & 1.03 & 0.88 & 1.21 \\
\hline \multicolumn{7}{|l|}{ Sex of the child } \\
\hline \multicolumn{7}{|l|}{ Male† } \\
\hline Female & 1.14 & 0.87 & 1.47 & $1.18^{\star \star \star}$ & 1.06 & 1.31 \\
\hline \multicolumn{7}{|l|}{ Mother's age (at child's birth) } \\
\hline \multicolumn{7}{|l|}{$\leq 19$ years $\dagger$} \\
\hline 20-24 years & 0.70 & 0.47 & 1.05 & $0.67^{\star \star \star}$ & 0.56 & 0.79 \\
\hline 25-29 years & 0.78 & 0.49 & 1.23 & $0.81^{\star *}$ & 0.67 & 0.99 \\
\hline $30+$ years & 0.83 & 0.48 & 1.45 & 1.04 & 0.84 & 1.29 \\
\hline \multicolumn{7}{|l|}{ BMI } \\
\hline \multicolumn{7}{|l|}{ Low† } \\
\hline High & 1.09 & 0.77 & 1.54 & 1.00 & 0.89 & 1.13 \\
\hline Missing & $3.26^{\star \star \star}$ & 1.58 & 6.75 & 0.87 & 0.48 & 1.58 \\
\hline \multicolumn{7}{|l|}{ Caste } \\
\hline \multicolumn{7}{|l|}{$\mathrm{SC}+$} \\
\hline ST & 1.07 & 0.55 & 2.06 & 0.88 & 0.71 & 1.09 \\
\hline Others & 0.78 & 0.57 & 1.06 & 0.95 & 0.83 & 1.08 \\
\hline \multicolumn{7}{|l|}{ Religion } \\
\hline \multicolumn{7}{|l|}{ Hindu† } \\
\hline Muslim & 1.43 & 0.95 & 2.14 & 0.94 & 0.81 & 1.10 \\
\hline Others & 1.34 & 0.87 & 2.07 & 0.99 & 0.41 & 2.40 \\
\hline \multicolumn{7}{|l|}{ Birth interval } \\
\hline \multicolumn{7}{|l|}{ First birth† } \\
\hline Less than 24 months & 1.37 & 0.95 & 1.97 & $1.56^{\star \star \star}$ & 1.34 & 1.81 \\
\hline 24 or more months & 0.97 & 0.69 & 1.36 & $0.82^{\star \star}$ & 0.70 & 0.96 \\
\hline \multicolumn{7}{|l|}{ Mother's education } \\
\hline Illiterate† & & & & & & \\
\hline Primary & $0.60^{\star \star}$ & 0.36 & 0.98 & 0.97 & 0.83 & 1.12 \\
\hline Secondary & 0.71 & 0.48 & 1.03 & $0.77^{\star \star \star}$ & 0.67 & 0.89 \\
\hline Higher & $0.51^{\star *}$ & 0.27 & 0.93 & $0.48^{\star \star \star}$ & 0.35 & 0.66 \\
\hline
\end{tabular}




\begin{tabular}{|c|c|c|c|c|c|c|}
\hline \multirow[b]{3}{*}{ Covariates } & \multicolumn{3}{|c|}{ Good-performing states } & \multirow[b]{3}{*}{ HR } & \multirow{2}{*}{\multicolumn{2}{|c|}{$\begin{array}{l}\text { Poor-performing states } \\
95 \% \mathrm{Cl} \text { for } \exp (\beta)\end{array}$}} \\
\hline & \multirow[b]{2}{*}{ HR } & \multicolumn{2}{|c|}{$95 \% \mathrm{Cl}$ for $\exp (\beta)$} & & & \\
\hline & & Lower & Upper & & Lower & Upper \\
\hline \multicolumn{7}{|l|}{ Poorest† } \\
\hline Poorer & 1.70 & 0.88 & 3.26 & 0.89 & 0.77 & 1.02 \\
\hline Richer & 1.18 & 0.60 & 2.34 & 0.84 & 0.68 & 1.03 \\
\hline Richest & 0.88 & 0.42 & 1.86 & $0.61^{\star \star \star}$ & 0.45 & 0.81 \\
\hline
\end{tabular}

${ }^{\star * \star} \mathrm{P}<0.01,{ }^{\star \star} \mathrm{p}<0.05$.

†Reference category.

BMI, body mass index; MP, Madhya Pradesh; NA, not available; SC, scheduled caste; ST, scheduled tribe; UP, Uttar Pradesh.

states have been persistent outliers with respect to underperformance since 1992.

The analysis in this paper reveals that India has made progress in terms of reducing infant and child mortality, but this progress has been relatively slow from 1992 to 2006. During this period less than $10 \%$ reduction in infant mortality was observed in a number of states, namely Chhattisgarh, Jharkhand, Rajasthan, Andhra Pradesh, Jammu and Kashmir, and Manipur. In contrast, much of the reduction in infant and child mortality was observed during the 2006-2016 period. Even the worst-performing states had more than $35 \%$ reduction in infant mortality. In addition, the variation in performance between the worst-performing and best-performing states too drastically reduced over time.

Hence, in spite of significant reduction in infant and child mortality rates in recent years, a lot needs to be done especially with respect to underperforming states which are persistent outliers. There are a number of policy implications from our study. It is important that policy makers target the underperforming states (upper outliers) as identified by the funnel plot in order to ensure reduction in variation between the states. These should fall down within the $95 \%$ CI. In addition, policy makers should focus on the larger states lying above the CI on the right, namely the high-impact states, as these represent the biggest population states with the potential for the most significant improvements in terms of reduction of IMR and U5MR.

The current policy in India is to focus on 18 states, including 8 empowered action group states, ${ }^{23}$ which are poor-performing states, targeting families below the poverty line. There is a need for a more flexible approach to reducing child mortality among underperforming states. Selective targeting of lower socioeconomic groups may be necessary. However, our study suggests that states like MP, UP, Chhattisgarh and Bihar would benefit from a rapid scale-up of interventions that reduce the average child mortality, irrespective of the socioeconomic groups that may benefit from the reductions.
Another important aspect to consider is the contribution of neonatal mortality to the total infant mortality. Over the years, the proportion of neonatal mortality has been on the rise from $62 \%$ in 1992 to $73 \%$ in 2016 . In addition, even low-performing states like UP, MP, Bihar and Chhattisgarh experience high neonatal mortality especially in rural areas. This observation has important implications for policy makers. India has achieved reduction in infant mortality mainly due to reduction in postneonatal mortality rates, which are comparatively more amenable to existing set of interventions. However, existing strategies and interventions on their own may not be adequate and a new set of high tech and expensive strategies would be needed if the focus is to shift to neonatal mortality.

Cox regression analysis shows that in well-performing states, only mothers' education was significantly associated with increased ratio of infant mortality. However, in poor-performing states, sex of the child, mothers' age at childbirth, birth interval, age of the child, mothers' education and wealth index emerge as significant predictors of infant mortality.

Similar to previous studies our results also show that female child had a higher risk of death during infancy than a male child in the poor-performing states in India. ${ }^{24-27}$ The reason of excess female infant mortality could be human intervention at different stages of life cycle. Numerous studies have recognised gender gap in vaccination, ${ }^{28}{ }^{29}$ breast feeding, ${ }^{30}$ allocation of food, nutrition (milk, fats, cereals and sugars), and even medical care and expenses. ${ }^{31-33}$ These deliberate negligence were more pronounced in the poor-performing states, leaving female infants at higher risk of mortality.

After adjusting for other covariates in the model, this study suggests that less than 24 months of birth interval are invariably more hazardous in terms of infant mortality. Various studies have documented the significant effect of birth interval and infant mortality. ${ }^{345}$ Short preceding intervals are associated with enhanced risk of prematurity and low birth weight for gestational age. ${ }^{36}$ 
Also cross-infection, less maternal attention and limited household resources between closely spaced siblings may be probable pathways through which infant mortality would seem high. ${ }^{37}{ }^{38}$ The poor-performing states which had higher fertility than well-performing states also had lower birth interval.

Compared with other countries in the region, it is evident that even poorer nations like Bangladesh and Nepal have performed better than India. ${ }^{39-41}$ India's poor performance can also be noted with respect to immunisation coverage, child anaemia and nutrition. Despite its economic progress and significant efforts since the 1980s, for example with the Expanded Programme on Immunization and the Universal Immunization Programme, India has the lowest immunisation coverage rates in Asia. ${ }^{40}$ Only $62 \%$ of children between the age of 12 and 23 months receive the recommended vaccinations. ${ }^{15}$ The prevalence rate of anaemia in Indian children below the age of 5 is as high as $60 \%$. Even in richer states like Maharashtra and Gujarat, the percentage of children who are underweight is $36 \%$ and $40 \%$, respectively. ${ }^{15}$ Obviously, these figures are significantly worse for the poorer performing states identified in our study. Reddy et $a l^{42}$ in their recent call to action for universal health coverage also mention the limited health gains achieved by India over the last decade.

It is therefore not surprising to see a number of initiatives launched by the GOI in recent years. The National Rural Health Mission (NRHM) in 2005, which is the flagship programme of the GOI, attempts to meet people's health needs particularly in rural areas. ${ }^{23}$ It aims to reduce child and maternal mortality by strengthening the rural health system and introducing innovative public-private partnerships. Recognising that the past public health expenditure is inadequate ( $1 \%$ of its gross domestic product [GDP]), the NRHM aimed to double this expenditure by 2012 and increase its health expenditure to $3 \%$ of its GDP. ${ }^{43}$ Similarly, through Accredited Social Health Activist, it aims to address the need for a community worker to achieve universal coverage especially in the priority states. A good example of the role of community healthcare workers in reducing infant and child mortality is provided in a recently published study in Lancet Global Health by Tripathy $e t a l,{ }^{44}$ and subsequently the Call to Action for Child Survival and Development, and thereafter Reproductive, Maternal, Newborn, Child and Adolescent Health (RMNCH+A) strategic framework in 2013. The RMNCH+Astrategy is based on a continuum-of-care approach and defines integrated packages of services for different stages of life. More recently, newer initiatives like web-enabled tracking of pregnant women to ensure antenatal, intranatal and postnatal care; Janani Shishu Suraksha Karyakaram, which entitles all pregnant women delivering in public health institutions to absolutely free delivery, including caesarean section and free transport; and Rashtriya Bal Swasthya Karyakram, an introduction of child health screening for $4 \mathrm{Ds}$, that is, defects at birth, deficiencies, diseases and development delays, ${ }^{45}$ are landmark policies in reducing infant and child mortality. These packages provide a framework for delivering services at the state and district levels.

Policy makers could benefit from further analysis to target the underperforming states. For example, it would be necessary to analyse inequalities with respect to infant and child mortality across states and within states. ${ }^{46}$ For the first time district-level data are available, and such analysis could guide policy makers with micro-level planning, and cluster analysis could help with selective targeting of specific districts. Few previous studies cited the role of family-level clustering of infant deaths in the low-performing states. ${ }^{47}$

From our analysis, it appears that the trend in reducing IMR and U5MR is headed in the right direction. Even so, there is huge variation between states and within states. However, a blanket approach to reducing infant and child mortality in all underperforming states of India may not be the best option. Depending on a state's performance and the socioeconomic differentials, policy makers may wish to be flexible in their approach in reducing infant and child mortality as discussed in this paper. Given the greater contribution of neonatal mortality, India's challenge in reducing infant mortality would depend largely on how it addresses the issue of neonatal deaths.

\section{CONCLUSIONS}

The results of this study confirm that to bring the overall Indian national average of IMR and U5MR to a more respectable level, policy makers will have to target the underperforming large states and population groups where mortality rates are still high. This is particularly so when the improvements with respect to infant and child mortality have been unevenly distributed across states and population groups. As India continues to reduce its infant and child mortality, the challenge is to accelerate its reform process by adopting a different strategy. To a large extent, India's underperforming states and its approach to reducing neonatal mortality will determine its success or failure in reducing infant and child mortality in the future.

Contributors MB, LKD and MR were involved in planning, conceptualising and writing the manuscript. LKD and MR were involved in data analysis, statistical methods and interpretation. MR and PD were involved in literature review and analysis of data. VP contributed towards maps and the concept of funnel plot. Each author contributed to the drafting, reviewing and revising of the manuscript. All authors have seen and approved the final version of this manuscript.

Funding The authors have not declared a specific grant for this research from any funding agency in the public, commercial or not-for-profit sectors.

Competing interests None declared.

Patient consent for publication Not required.

Provenance and peer review Not commissioned; externally peer reviewed.

Data sharing statement NFHS data series 1-4 were used. This data set is available in a public domain.

Open access This is an open access article distributed in accordance with the Creative Commons Attribution Non Commercial (CC BY-NC 4.0) license, which permits others to distribute, remix, adapt, build upon this work non-commercially, 
and license their derivative works on different terms, provided the original work is properly cited, appropriate credit is given, any changes made indicated, and the use is non-commercial. See: http://creativecommons.org/licenses/by-nc/4.0/.

\section{REFERENCES}

1. Stockwell EG, Swanson DA, Wicks JW. Economic status differences in infant mortality by cause of death. Public Health Rep 1988;103:135-42.

2. United Nations. Millennium development goals. New York: World Summit, 2005.

3. WHO. Global health observatory data. 2018 http://www.who.int/gho/ child_health/mortality/mortality_under_five_text/en/

4. United Nations. The millennium development goals report. 2012.

5. UNICEF (2017). Levels and trends in child mortality report 2017. UN Inter-agency Group for child mortality estimation. https://www.unicef. org/publications/index_101071.html

6. SRS (2016). SRS Statistical Report. Office of the Registrar general \& census commissioner, india ministry of home affairs government of India. http://www.censusindia.gov.in/vital_statistics/SRS_Report_ 2016/8.Chap\%204-Mortality\%20Indicators-2016.pdf

7. UNICEF. Infant and child mortality in India: Levels, trends and determinants. 2012 www.unicef.org/india/Report.pdf

8. Spiegelhalter D. Funnel plots for institutional comparison. Qual Saf Health Care 2002;11:390-a-1.

9. Spiegelhalter DJ. Funnel plots for comparing institutional performance. Stat Med 2005;24:1185-202.

10. Jones HE, Ohlssen DI, Spiegelhalter DJ. Use of the false discovery rate when comparing multiple health care providers. J Clin Epidemiol 2008;61:232-40.

11. Gale CP, Roberts AP, Batin PD, et al. Funnel plots, performance variation and the myocardial infarction national audit project 2003 2004. BMC Cardiovasc Disord 2006;6:34.

12. Aylin P, Alves $B$, Best $N$, et al. Comparison of UK paediatric cardiac surgical performance by analysis of routinely collected data 1984-96: was Bristol an outlier? Lancet 2001;358:181-7.

13. Davies E, Mak V, Ferguson J, et al. Using funnel plots to explore variation in cancer mortality across primary care trusts in South-East England. J Public Health 2008;30:305-12.

14. Madden $\mathrm{P}$, Coupland V, Møller $\mathrm{H}$, et al. Using maps and funnel plots to explore variation in place of death from cancer within London, 2002-2007. Palliat Med 2011;25:323-32.

15. International Institute for Population Sciences (IIPS) and ICF. National family health survey (NFHS-4), 2015-16. India Mumbai: IIPS, 2017.

16. International Institute for Population Sciences (IIPS) and Macro International. National family health survey (NFHS-3), 2005-06. India Mumbai: IIPS, 2007.

17. International Institute for Population Sciences (IIPS). National family health survey (MCH \& family planning), India 1992-93. IIPS: Bombay, 1995.

18. Dandona L, Dandona R, Kumar GA, et al. Nations within a nation: variations in epidemiological transition across the states of India, 1990-2016 in the global burden of disease study. The Lancet 2017;390:2437-60.

19. Schoumaker B. Quality and consistency of DHS fertility estimates, 1990 to 2012 (DHS Methodological Reports No. 12). Rockville: ICF International. Google Scholar, 2014.

20. Cox DR. Regression models and life-tables. Journal of the Royal Statistical Society 1972;34:187-220.

21. Reidpath DD, Allotey P. Infant mortality rate as an indicator of population health. J Epidemiol Community Health 2003;57:344-6.

22. UNICEF India. Resources, fact sheet. http://www.unicef.org/india/ resources_170.htm (Accessed on 12th May 2013).
23. NRHM Planning Commission. Faster, sustainable and more inclusive growth: an approach to the twelfth five year plan (2012-17). New Delhi: Government of India, 2012.

24. Arnold F, Choe MK, Roy TK. Son preference, the family-building process and child mortality in India. Popul Stud 1998;52:301-15.

25. Kishor S. Women's health in India: Risk and vulnerability,. In: Das Gupta M, Krishnan TN, Chen LC, Gender differentials in child mortality: a review of the evidence: Oxford University, 1995:19-54.

26. Ranjan M, Dwivedi LK, Mishra R, et al. Infant mortality differentials among the tribal and non-tribal populations of Central and Eastern India. Int J Popul Stud 2017;2:26-43.

27. Claeson M, Bos ER, Mawji T, et al. Reducing child mortality in India in the new millennium. Bull World Health Organ 2000;78:1192-9.

28. Arokiasamy P. Regional patterns of sex bias and excess female child mortality in India. Population 2004;59:833-63.

29. Osters E. Proximate sources of population sex imbalance in India. Demography 2009;46:325-39.

30. Jayachandran S, Kuziemko I. Why do mothers breastfeed girls less than boys? Evidence and implications for child health in India. Q J Econ 2011;126:1485-538.

31. Bhattacharya J, Lakdawalla D. Does Medicare benefit the poor? J Public Econ 2006;90:277-92.

32. Gupta MD. Selective Discrimination against female children in rural Punjab, India. Popul Dev Rev 1987;13:77.

33. D'Souza S, Chen LC. Sex differentials in mortality in rural Bangladesh. Popul Dev Rev 1980;6:257-70.

34. Pandey A. Infant and child mortality in India. India, 1998.

35. Sahu D, Nair S, Singh L, et al. Levels, trends \& predictors of infant \& child mortality among scheduled tribes in rural India. Indian J Med Res 2015;141:709.

36. Conde-Agudelo A, Rosas-Bermúdez A, Kafury-Goeta AC. Birth spacing and risk of adverse perinatal outcomes: a meta-analysis. JAMA 2006;295:1809-923.

37. Boerma JT, Bicego GT. Preceding birth intervals and child survival: searching for pathways of influence. Stud Fam Plann 1992;23:243-56.

38. Victora CG, Wagstaff A, Schellenberg JA, et al. Applying an equity lens to child health and mortality: more of the same is not enough. Lancet 2003;362:233-41.

39. Boerma JT, Bryce J, Kinfu Y, et al. Mind the gap: equity and trends in coverage of maternal, newborn, and child health services in 54 Countdown countries. Lancet 2008;371:1259-67.

40. WHO. Accelerating progress towards achieving maternal and child health MDGs 4 \& 5 in South-East Asia. 2008.

41. UNICEF. The State of Asia-Pacific's Children (Child Survival). 2008 http://www.unicef.org/sapc08/report/report.php.

42. Reddy KS, Patel V, Jha P, et al. Towards achievement of universal health care in India by 2020: a call to action. Lancet 2011;377:760-8.

43. Nair KRG. Malnourishment among children in India: A regional analysis. Economic and Political Weekly 2007;42:37.

44. Tripathy P, Nair N, Sinha R, et al. Effect of participatory women's groups facilitated by accredited social health activists on birth outcomes in rural eastern india: a cluster-randomised controlled trial Lancet Glob Health 2016;4:e119-28.

45. Press Information Bureau, Government of India, Ministry of Health and Family Welfare. Steps by Government to reduce infant mortality rate. 2013 http://pib.nic.in/newsite/PrintRelease.aspx?relid=101932

46. Bhatia $M$, Ranjan $M$, Dixit $P$, et al. Mind the gap: temporal trends in inequalities in infant and child mortality in India (1992-2016). SSM Popul Health 2018;5:201-9.

47. Dwivedi LK, Ranjan M. Sibling Death Clustering Among the Tribes of Central and Eastern India: An Application of Random Effects Dynamic Probit Model. Demography and health issues: Springer, Cham, 2018:337-55. 